\title{
Risk assessment of the
}

\section{occurrence of black aspergilli on \\ grapes grown in an alpine region under a climate change scenario}

\author{
Journal Article \\ Author(s): \\ Storari, Michelangelo; Broggini, Giovanni A.L.; Bigler, Laurent; Cordano, Emanuele; Eccel, Emanuele; De Filippi, Riccardo; \\ Gessler, Cesare; Pertot, Ilaria
}

Publication date:

2012-11

Permanent link:

https://doi.org/10.3929/ethz-b-000056793

Rights / license:

In Copyright - Non-Commercial Use Permitted

Originally published in:

European Journal of Plant Pathology 134(3), https://doi.org/10.1007/s10658-012-0043-0 


\title{
Risk assessment of the occurrence of black aspergilli on grapes grown in an alpine region under a climate change scenario
}

\author{
Michelangelo Storari • Giovanni A. L. Broggini • \\ Laurent Bigler • Emanuele Cordano • \\ Emanuele Eccel • Riccardo De Filippi • \\ Cesare Gessler • Ilaria Pertot
}

Accepted: 13 July 2012 / Published online: 9 August 2012

(C) KNPV 2012

\begin{abstract}
Members of the Aspergillus section Nigri, also known as black aspergilli, are responsible for the ochratoxin A (OTA) and fumonisins contamination of wine. The presence of black aspergilli in vineyards has been investigated extensively in warm climates, in which the incidence of these aspergilli on grapes and levels of OTA contamination of wines are commonly high. However, a detailed description of black
\end{abstract}

Electronic supplementary material The online version of this article (doi:10.1007/s10658-012-0043-0) contains

supplementary material, which is available to authorized users.

M. Storari · G. A. L. Broggini · C. Gessler $(\bowtie)$

Plant Pathology Group, Institute of Integrative Biology,

ETH Zurich,

8092 Zürich, Switzerland

e-mail: cesare.gessler@usys.ethz.ch

L. Bigler

Institute of Organic Chemistry, University of Zurich,

8057 Zurich, Switzerland

E. Cordano $\cdot$ E. Eccel $\cdot$ I. Pertot

Sustainable Agro-ecosystems and Bioresources

Department, IASMA Research and Innovation Centre,

Fondazione Edmund Mach. Via E. Mach 1,

38010 San Michele all'Adige, TN, Italy

R. De Filippi

Bruno Kessler Foundation,

Via Sommarive 18,

38100 Povo, TN, Italy aspergilli populations is needed in wine-producing cool regions to establish a baseline in view of the strengthening of temperature increase and in case of summer rainfall decrease. With this in mind, we isolated and characterized black aspergilli from grapes grown in an alpine region in Northern Italy (Trentino) during a 3-year sampling. Black aspergilli were isolated from around $10 \%$ of the grape berries and most of the isolates were classified as A. niger, A. tubingensis and $A$. uvarum. A. carbonarius was isolated only once. OTA production was detected only in the A carbonarius isolate and in one $A$. niger. Most of $A$. niger isolates were able to produce fumonisins. The presence of mycotoxins biosynthesis genes was assessed in A. niger isolates. An15g07920, a polyketide synthase (PKS) gene involved in OTA biosynthesis, was detected by PCR only in the single ochratoxigenic isolate. This strong correlation was not observed for anfum 1, anfum6 and anfum8, three genes included in the $A$. niger fumonisin biosynthesis gene cluster, which were detected in different $A$. niger isolates not able to produce fumonisins. Projections of mean daily temperatures and monthly rainfall indicate that the presence of black aspergilli on grapes grown in vineyards of these valleys will probably increase in the future.

Keywords Ochratoxin A · Fumonisins .

A. carbonarius $\cdot$ A. niger $\cdot$ A. tubingensis 


\section{Introduction}

Mycotoxins are products of fungal secondary metabolism that have toxic effects on humans and/or animals (Bennett and Klich 2003). In recent years, several reports have been published concerning the natural occurrence of different mycotoxins in wine (Zimmerli and Dick 1996; Scott et al. 2006; Mogensen et al. 2010a). The most important toxic contaminant of fungal origin that may be found in wine and other grape products is ochratoxin A (OTA), a nephrotoxic, immunotoxic, teratogenic and carcinogenic polyketidederived mycotoxin (Hocking et al. 2007; PfohlLeszkowicz and Manderville 2007). The first report of the natural occurrence of OTA in wine was published in 1996 (Zimmerli and Dick 1996). In 2005, the EU established maximum permissible concentration of $2 \mu \mathrm{g}^{-1}$ OTA in wine (Commission Regulation 2005). Members of the Aspergillus section Nigri, also known as black aspergilli, are responsible for the production of OTA on grapes and the subsequent contamination of wine, grape juice and raisins (Perrone et al. 2007). A. carbonarius is considered to be the main OTA-producing species affecting grapes. In fact, most of the studied isolates of this species produce OTA (Perrone et al. 2007). Another ochratoxigenic Aspergillus species of the section Nigri that has been isolated from grapes is $A$. niger, but only 2-20\% of the strains of this species produce OTA (Perrone et al. 2007). Recently, the inability of most $A$. niger strains to produce OTA was shown to be related to the absence of an15g07920, a polyketide synthase (PKS) required for OTA (Storari et al. 2010; Yamada et al. 2011). This same PKS gene was used by Castellá and Cabañes (2011) to develop a real-time PCR-based system for the detection of ochratoxigenic strains of $A$. niger in food. A. tubingensis, a species included in the $A$. niger aggregate, has also been reported to be potentially ochratoxigenic (Medina et al. 2005; Perrone et al. 2006). However, this conclusion was not confirmed by the reexamination of the strains by other authors (Nielsen et al. 2009; Storari et al. 2010). Another nonochratoxigenic species of black aspergilli that is frequently isolated from grapes grown in European vineyards is the uniseriate A. uvarum (Perrone et al. 2007; Perrone et al. 2008).

An additional toxicological risk related to black aspergilli is the ability of $A$. niger to synthesize fumonisins, a group of polyketide-derived carcinogenic mycotoxins, which were originally described as products of the genus Fusarium (Logrieco et al. 2010a). The first evidences of the ability of $A$. niger to produce fumonisins followed the discovery of a putative fumonisin biosynthesis gene cluster in the sequenced $A$. niger genome (Pel et al. 2007; Frisvad et al. 2007). It is now clear that the majority ( $>50 \%)$ of the A. niger strains that have been isolated from agricultural products can produce different fumonsins of the $\mathrm{B}$ series, in particular $\mathrm{FB}_{2}, \mathrm{FB}_{4}$ and $\mathrm{FB}_{6}$ (Noonim et al. 2009; Månsson et al. 2010; Mogensen et al. 2010b). A study carried out by Susca et al. (2010) demonstrated a correlation between fumonisins production and the presence of anfum 8 , an $\alpha$-oxoamine synthase required for fumonisin biosynthesis, in strains of $A$. niger isolated from grapes. The first reports of the contamination of wines with fumonisin revealed naturally occurring $\mathrm{FB}_{2}$ concentrations of 0.1 to $25 \mu \mathrm{g} / \mathrm{l}$ (Logrieco et al. 2010b; Mogensen et al. 2010a).

Meteorological conditions have been shown to play a major role in OTA contaminations of grapes and the incidence of black aspergilli on berries (Battilani et al. 2006a; Battilani et al. 2006b). High temperatures from veraison to harvest are a risk factor for the increase of OTA contamination in grapes and wines (reviewed by Visconti et al. 2008). In fact, the OTA contamination of wines produced in the European Community was found to be higher in samples from southern areas than those from the northern areas (Zimmerli and Dick 1996; Otteneder and Majerus 2000). A geostatistical analysis performed on the results of the surveys of the incidence of black aspergilli in vineyards of different Mediterranean countries evidenced a positive NorthSouth gradient (Battilani et al. 2006b; Visconti et al. 2008). In the analysis of Battilani et al. (2006b), the sum of temperatures and rain during August were used to generate thermo-wetness maps showing trends similar to the incidence of black aspergilli on grapes. The distribution of black aspergilli species also appears to be influenced by meteorological conditions. The incidence of $A$. carbonarius has been shown to be higher on grapes from Southern Mediterranean regions, while A. tubingensis and A. niger are more widespread (Battilani et al. 2006b; Perrone et al. 2007; Lucchetta et al. 2010). The high incidence of black aspergilli on grapes cultivated in warm environments can be explained by their relatively high optimum growth temperature that allows them to grow better at high temperatures compared to other grape-associated filamentous 
fungi (Valero et al. 2005; Leong et al. 2006). In reflection of this pattern of distribution, most of the investigations of the presence of black aspergilli in European vineyards had been conducted in vineyards of warm regions and little is known about the populations of black Aspergillus species in colder wine-producing ones (Serra et al. 2003; Medina et al. 2005; Tjamos et al. 2006). However, the climate change and the subsequent increase in temperature expected in Europe are likely to influence the distribution of mycotoxigenic fungi, including black aspergilli, leading to the establishment of these pathogens in regions where these species had not been widely found before (IPCC 2007; Paterson and Lima 2010; Magan et al. 2011). To better evaluate and prepare for present and future risks of OTA and fumonisins contamination of grapes, the distribution of mycotoxin-producing black aspergilli in vineyards needs to be described in more details. In view of the anticipated climate change, this is particularly important for environments characterized by meteorological conditions in which the risk of the presence of black aspergilli is currently low. Information collected from vineyards in these regions concerning the presence of black aspergilli, the species composition of existing populations and the frequency of biosynthesis genes in potentially toxigenic species can then be used as a reference baseline to predict the risk of mycotoxin contamination in these cooler grape-growing regions and to develop effective tools for the early detection of pathogens in the field.

We used vineyards in alpine valleys in northern Italy (Trentino region) as case study to evaluate the present and future risk of the presence of black aspergilli for cool climate grape-producing regions. Black aspergilli isolated from ripe grapes during a three-year survey were characterized using molecular methods and their abilities to produce OTA and fumonisins were evaluated. The presence of an15g07920, a PKS involved in OTA production, and three genes essential for fumonisin biosynthesis (anfum1, anfum6 and anfum8) was assessed in all $A$. niger isolates to evaluate their use as targets in molecular detection tests. Moreover, the thermowetness classes developed by Battilani et al. (2006b) were used with projections of temperature and rain to evaluate the possible increase of the presence of black aspergilli on grapes of this region in the future.

\section{Materials and methods}

Meteorological data analysis

Sum of daily rainfall and temperature in the region of sampling Summation of daily rainfall $(\mathrm{mm})$ and mean daily temperature $\left({ }^{\circ} \mathrm{C}\right.$ day) gathered from stations in the three regions of sampling (San Michele all'Adige station for Rotaliana plain, Rovereto station for Adige plain and Arco station for Sarca valley) were calculated for the period between 1st and 31st August starting from 1978. Meteorological data were compared to the nine thermo-wetness classes described by Battilani et al. (2006b).

Meteorological series Time series of temperature and rainfall from Trentino were mostly obtained from the local meteorological service (Meteotrentino), others from Fondazione Edmund Mach. Also series from surrounding areas were considered. They have been supplied by the Autonomous Province of Bolzano (PAB), ARPA Veneto (ARPAV), and ARPA Lombardia (ARPAL). The stations were selected based on their geographic position in order to sample the region as homogeneously as possible, also considering altitudinal displacements of sites. Sufficient length of the available series was also considered in the selection. The location of the stations whose time series were used is indicated in the Supplementary Figure 1. The statistical downscaling model was calibrated on the 50 -year period $1^{\text {st }}$ January $1958-31^{\text {st }}$ December 2007. The total number of time series was 36,7 of them being available only as precipitation series.

Climate modelling To apply the modelling of the presence of Aspergillus both temperature and precipitation projections in August are necessary. In general, globalscale circulation climate models (GCMs) yield their outputs on a very coarse grid, typically 1 to $3^{\circ}$ wide. To calculate the high-resolution climate projections in the area, a statistical downscaling of the large-scale output of climate models was carried out. The latter allows to project GCM output on single sites, where sufficiently long and reliable climatic series exist.

For temperature, a statistical downscaling was carried out by a Canonical Correlation Analysis (CCA), according to the methodology described in Tomozeiu et al. (2007). The CCA method consists in identifying optimal predictor-predictand pairs of patterns, where 
the correlation between two corresponding patterns is maximal (von Storch 1995). Possible predictors are large-scale atmospheric patterns, like geopotential height at 850 and $500 \mathrm{hPa}$, mean-sea-level pressure and atmospheric temperature.

The implementation consisted of a two-step procedure. First, the CCA model was calibrated for a period when both instrumental series and meteorological reanalysis were available. The predictor fields were retrieved from the European Centre ECMWF's ERA-40 re-analysis (Kållberg et al. 2005). Then, the model was applied to the large-scale output of a set of seven models selected in the European project "Ensembles" (van der Linden and Mitchell 2009). The ensemble median of the output of simulations carried out under the A1B scenario was chosen as the most robust estimate for a likely projection. The seasonallyaveraged values were detailed at the monthly scale by a spline interpolator function. Finally, the latter were given as input to a weather generator to produce daily series of mean temperature, necessary to calculate thermal sums. This item was carried out with a multi-site weather generator (RMAWGEN: http:// cran.r-project.org/) developed by Cordano and Eccel (Cordano and Eccel 2011), which enabled meeting the meteorological and temporal consistency of the simulated series, a necessary feature for the eventual spatial interpolation.

Because of the more simple input required for precipitation in the infection model (August monthly sums), the expected values were retrieved by applying the per cent change (with respect to the 1961-1990 climatic benchmark, which was calculated, in the study area, from the instrumental series of the area) projected by a regional-scale multi-model ensemble mean within the above-mentioned project "Ensembles". Again, the seasonal projected changes were applied to the month of August, which, in the Trentino region, amounts on average to $1 / 3$ of the summer total.

Data were simulated for three 30 -year periods. The future projection periods are the standard ones for the "Ensembles" project (whose GCM runs were used for the statistical downscaling): 2021-2050 and 20712099. The observational period (climatic means of 1978-2007) was taken as a benchmark of the present conditions. Also for this reference period, covered by meteorological observations, daily temperature series were simulated by the weather generator, for the sake of homogeneity with the two projections.
All the data processing of the climate section were carried out by the free statistical software $\mathrm{R}$ (R Development Core Team 2011).

Mapping classes of thermo-wetness using spatial temperature and precipitation interpolation Meteorological series, air temperature and precipitation, downscaled at point locations were interpolated by an optimal interpolation method (Uboldi et al. 2008) for air temperature and a Kriging interpolation method (Meteotrentino 2008) for precipitation. The algorithm uses the digital terrain model as reference background to obtain daily average temperature and accumulated precipitation maps with a spatial resolution of $200 \mathrm{~m}$. Maps are loaded as raster datasets into GRASS GIS and classified using nine thermo-wetness classes, obtained by combining increasing thermal sum classes $\left({ }^{\circ} \mathrm{C}\right.$ day) and decreasing accumulated rainfall $(\mathrm{mm})$, both calculated for the month of August (Battilani et al. 2006b).

Vineyards, grape sampling and fungal isolation

A wide range of grape varieties was sampled in three different locations in Trentino region (Table 1) in September 2008 (12 vineyards), 2009 (15 vineyards) and 2010 (15 vineyards). Additional samples of "Fiano", which ripens in November, and "Nosiola Passito", a variety partially dried on nets in dry rooms to produce passito wine, were collected in November of 2008, 2009 and 2010. In each vineyard 10 healthy bunches were randomly collected along the two major diagonal transects (Battilani et al. 2006b). In the first year of isolation, five berries from each bunch were incubated on Rose Bengal agar (RBC; Oxoid, UK) supplemented with $250 \mathrm{mg}^{-1}$ chloramphenicol (Sigma-Aldrich, Switzerland) and kept at $25{ }^{\circ} \mathrm{C}$ for 7 days in the dark. However, to avoid the frequently observed growth of Rhizopus, Dichloran Rose Bengal Agar (DRBC; Oxoid, UK) supplemented with $250 \mathrm{mg} \mathrm{l}^{-1}$ chloramphenicol (Sigma-Aldrich, Switzerland) was used instead of RBC during the following 2 years of isolation. All grown Aspergillus colonies were collected and purified on potato dextrose agar (PDA; Oxoid, England). In 2008, an alternative fungal isolation procedure was used, in which we placed $1 \mathrm{ml}$ of a washing solution, obtained by shaking ( $3 \mathrm{~h}$, $150 \mathrm{rpm}) 20$ additional berries from each bunch in $100 \mathrm{ml} 0.01 \%$ Tween-80 (AppliChem, Germany) 
Table 1 Location of sampled vineyards
${ }^{1}$ Nosiola passito bunches were collected in November from drying nets

\begin{tabular}{|c|c|c|c|c|}
\hline Valley & Vineyards & Cultivar & Location (GIS) & Years of sampling \\
\hline \multirow[t]{9}{*}{ Rotaliana plain } & 1 & Merlot & $46.1890,11.1352$ & $2008,2009,2010$ \\
\hline & 2 & Merlot & $46.1961,11.1381$ & $2008,2009,2010$ \\
\hline & 3 & Chardonnay & $46.1892,11.1350$ & $2008,2009,2010$ \\
\hline & 4 & Chardonnay & $46.1844,11.1328$ & $2008,2009,2010$ \\
\hline & 5 & Nosiola & $46.1844,11.1328$ & $2008,2009,2010$ \\
\hline & 6 & Rebo & $46.1893,11.1362$ & 2009,2010 \\
\hline & 7 & Teroldego & $46.1900,11.1372$ & $2008,2009,2010$ \\
\hline & 8 & Pinot gris & $46.1881,11.1361$ & $2008,2009,2010$ \\
\hline & 9 & Pinot gris & $46.1816,11.1240$ & $2008,2009,2010$ \\
\hline \multirow[t]{3}{*}{ Adige valley } & 10 & Teroldego & $45.8780,11.0189$ & $2008,2009,2010$ \\
\hline & 11 & Merlot & $45.8790,11.0210$ & $2008,2009,2010$ \\
\hline & 12 & Pinot gris & $45.8775,11.0185$ & 2009,2010 \\
\hline \multirow[t]{5}{*}{ Sarca valley } & 13 & Merlot & $45.920,10.9022$ & 2009,2010 \\
\hline & 14 & Merlot & $45.9066,10.8557$ & 2009,2010 \\
\hline & 15 & Chardonnay & $45.9060,10.8547$ & 2009,2010 \\
\hline & 16 & Fiano & $46.0420,10.9544$ & $2008,2009,2010$ \\
\hline & 17 & Nosiola passito $^{1}$ & & $2008,2009,2010$ \\
\hline
\end{tabular}

solution, onto each plate of RBC agar. Fungal colonies were kept on PDA agar slants at $4{ }^{\circ} \mathrm{C}$ until use. Pesticides were applied according the regional IPM program.

DNA extraction and species determination

For the DNA extraction, all black Aspergillus isolates were grown for 7-14 days in 10-ml potato dextrose broth (PDB; Difco, USA) kept at $24{ }^{\circ} \mathrm{C}$ on a horizontal shaker $(150 \mathrm{rpm})$. The cultured mycelia were then recovered by centrifugation and lyophilized. DNA extraction was performed using the DNeasy ${ }^{\circledR}$ Plant Mini Kit (QIAGEN, Germany) according to the manufacturer's instructions. The species identity of each isolate was determined by sequencing a portion of the calmodulin gene using CL1 andCL2A primers (O'Donnell et al. 2000) following the protocol described by Serra et al. (2006) with minor modifications. Amplicons were sequenced using the ABI PRISM BigDye Terminator v3.0 ready reaction cycle sequencing kit (Applied Biosystems, USA) according to the manufacturer's instructions. The sequences were analyzed with the Sequencher version 4.2 software package (Gene Codes Corporation, USA) and aligned using ClustalW (BioEdit software version 7.0.0). The alignment output was entered in MEGA software, version 4.0 (Tamura et al. 2007) to generate phylogenetic trees (bootstrap analysis using NeighbourJoining with 1,000 replicates and default settings). Calmodulin sequences of the reference black aspergilli strains were obtained from the NCBI database (http:// www.ncbi.nlm.nih.gov/genbank/) and included in the phylogenetic analysis (Samson et al. 2007). Recently, a cryptic species called A. awamori was described inside the A. niger species (Perrone et al. 2011). Since strains of these two groups cannot be separated according to morphology or secondary metabolites production (including mycotoxins), we maintained the name $A$. niger also for the isolates of the subclade $A$. awamori.

In vitro production of mycotoxins

Isolates classified as $A$. carbonarius, A. niger or $A$. tubingensis were grown for 7 days at $24{ }^{\circ} \mathrm{C}$ in three point-inoculated Petri dishes containing $17.5 \mathrm{ml}$ of Czapek Autolysate (CYA; Pitt and Hocking 1997) and an equal amount of Yeast Extract Sucrose (YES; Bragulat et al. 2001) agar and were qualitatively tested for OTA production, as described by Bragulat et al. (2001) with minor modifications. An agar plug $(6 \mathrm{~mm}$ diam) was cut from the centre of each colony, introduced into a small vial and soaked with $0.5 \mathrm{ml}$ methanol. After a minimum of $60 \mathrm{~min}$ the extracts were 
filtered using a Millex-HV Filter (0.45 $\mu \mathrm{m}$, PVDF, $13 \mathrm{~mm}$; Millipore, USA) directly into HPLC vials. One extract from each plate was analysed with an HPLC apparatus equipped with a fluorescence detector. The other two extracts were stored at $4{ }^{\circ} \mathrm{C}$ and used as necessary for further analyses. Reference isolates $A$. niger ITEM 7096, $A$. niger ITEM 7097, $A$. niger 7098, A. carbonarius ITEM 5005, A. carbonarius ITEM 5010 and A. carbonarius ITEM 5012 from the ITEM collection (http://server.ispa.cnr.it/ITEM/ Collection/) were included as positive controls. The HPLC system (Jasco, Germany) was equipped with Jasco PU-980 pumps, a Jasco AS-2055 PLUS sampling system, a C18 column (Spherisorb ODS 2, 250× $4.6 \mathrm{~mm}, 5 \mu \mathrm{m}$; Waters, USA) and a Jasco 2020 PLUS fluorescence detector (excitation $330 \mathrm{~nm}$, emission $460 \mathrm{~nm}$; gain:1000; response STD). The system was controlled using Jasco Chrompass software. The mobile phase consisted of $57 \%$ acetonitrile, $41 \%$ water and $2 \%$ acetic acid (isocratic) pumped at $1.0 \mathrm{ml} \mathrm{min}^{-1}$. The injection volume was $20 \mu \mathrm{l}$. The retention time of the OTA standard $\left(10 \mu \mathrm{g} \mathrm{ml}^{-1}\right.$ in acetonitrile; analytical standard; Sigma-Aldrich, Switzerland) was around 6 min. The detection limit of the HPLC apparatus was about $1 \mathrm{ng} \mathrm{ml}^{-1}$. OTA production was confirmed by analysing the first extract or the extracts stored at $4{ }^{\circ} \mathrm{C}$ running a second HPLC program consisting of a mobile phase composed of $45 \%$ acetonitrile, $52.5 \%$ water and $2.5 \%$ acetic acid (isocratic) pumped at $1.0 \mathrm{ml} \mathrm{m^{-1 }}$. The retention time of the OTA standard was around $13 \mathrm{~min}$. The OTA production of the A. niger isolates collected in 2008 was evaluated previously (Storari et al. 2010).

A. niger isolates grown for 7 days at $24{ }^{\circ} \mathrm{C}$ in Petri dishes containing $17.5 \mathrm{ml}$ of CYA agar with $5 \% \mathrm{NaCl}$ (CYAS; Frisvad and Samson 2004) were qualitatively tested for fumonisins production, as described by Frisvad et al. (2007) with minor modifications. Two agar plugs $(6 \mathrm{~mm}$ diam.) were cut from the centre of two colonies from each plate and extracted separately with $750 \mu \mathrm{l}$ of $75 \% \mathrm{MeOH}$ in $\mathrm{H}_{2} \mathrm{O}(v / v)$ in small vials using ultrasonication $(50 \mathrm{~min})$. The extracts were filtered using PTFE $0.45 \mu \mathrm{m}$ filters (Macherey-Nagel, Switzerland) and $1 \mu$ l was directly injected for the analysis. The HPLC-ESI-MS and MS/MS analysis were performed on a Water Acquity UPLC (Waters, Milford, USA) connected to a Bruker maxis high-resolution quadrupole time-of-flight mass spectrometer (Bruker Daltonics, Bremen, Germany). An Acquity BEH C18
HPLC column $(1.7 \mu \mathrm{m}, 2.1 \times 50 \mathrm{~mm}$ fitted with a $2 \times$ $2 \mathrm{~mm}$ guard column) has been used with a mixture of $\mathrm{H}_{2} \mathrm{O}+0.1 \% \mathrm{HCOOH}(\mathrm{A})$ and $\mathrm{CH}_{3} \mathrm{CN}+0.1 \% \mathrm{HCOOH}$ (B) solvent ( $0.5 \mathrm{ml}$ flow rate, linear gradient from 10 to $100 \%$ B within 3 min followed by flushing with $100 \%$ $\mathrm{B}$ for $2 \mathrm{~min}$ ). The mass spectrometer was operated in the positive electrospray ionization mode at $4,500 \mathrm{~V}$ capillary voltage, $-500 \mathrm{~V}$ endplate offset, with a $\mathrm{N}_{2}$ nebulizer pressure of 1.4 bar and dry gas flow of $101 \mathrm{~min}^{-1}$ at $200{ }^{\circ} \mathrm{C}$. MS acquisitions were performed in the mass range from 50 to $1,000 \mathrm{~m} / \mathrm{z}$ at 30,000 resolution (full width at half maximum) and 3 scan per second. The MS instrument was optimized for maximum signal intensities of $\mathrm{FB}_{1}$ at $m / z$ 722. Masses were calibrated below $2 \mathrm{ppm}$ accuracy with a $2 \mathrm{mM}$ solution of sodium formate over $\mathrm{m} / \mathrm{z} 158$ up to 1450 mass range prior analysis. The lock mass signal of hexakis $(1 \mathrm{H},-1 \mathrm{H}, 2 \mathrm{H}-$ perfluoroethoxy)phosphazine at $\mathrm{m} / \mathrm{z} 622.22121$ was further used as lock mass during the HPLC run. $\mathrm{FB}_{1}$ and $\mathrm{FB}_{2}\left(50 \mu \mathrm{g} \mathrm{ml}^{-1}\right.$ in acetonitrile:water 50:50, analytical standard, Sigma-Aldrich) were used as standards. The limit of detection, determined by spiking in triplicate an agar plug cut from cultures of a fumonisins nonproducing $A$. niger and $A$. tubingensis strains with 50 $\mu \mathrm{L}$ of $\mathrm{FB}_{2}$ solutions at different concentrations, was about $0.3 \mu \mathrm{g} \mathrm{g}^{-1}$ agar. A. niger isolates for which it was not possible to detect fumonisins production were tested a second time using five agar plugs instead of one. The identification of $\mathrm{FB}_{4}$ and $\mathrm{FB}_{6}$ was based on mass, retention time, ion fragmentation and how these data related to data in the literature (Gelderblom et al. 2007; Nielsen et al. 2009; Månsson et al. 2010). Reference isolates $A$. niger CBS 113.46, A. niger CBS 554.65 and $A$. niger CBS 120.49 from Centraalbureau voor Schimmelcultures (The Netherlands), were included in our study as positive controls.

Amplification of mycotoxin biosynthesis genes

The presence of an15g07920 among A. niger isolates collected in Trentino in 2008 was already assessed in Storari et al. (2010). The same protocol was used to screen A. niger isolates of 2009 and 2010. All A. niger isolates were screened for the presence of the fumonisin biosynthesis genes anfum1 (an01g06930), anfum6 (an01g06820) and anfum8 (an01g06870). These genes are putative homologues of fum1, fum6 and fum 8 genes of $F$. verticillioides, which have been shown to be essential for the biosynthesis of fumonisin 
(Proctor et al. 2006). Anfum1 and anfum6 were amplified using the novel designed primer pairs Anfum1_f/r ( 5'-GCGGCAGCAAACGGTTACGC-3', 5' TCCGGAAGCGCCCTCGCTAT-3'; 369 bp) and Anfum6_f/r (5'- TCGGACCTGTTCGGCGCCTA -3', 5'- GCTAAGCCTGTCCCAGCGGC-3'; 488 bp). Each PCR reaction mixture $(25 \mu \mathrm{l})$ contained approximatively $5 \mathrm{ng}$ genomic DNA, $1 \mathrm{x}$ Dream Taq buffer

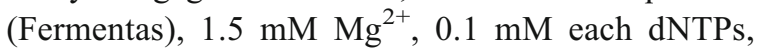
$0.2 \mu \mathrm{M}$ of each primer, $0.07 \mathrm{U} / \mu \mathrm{l}$ of Dream Taq (Fermentas) for anfum 1 amplification and approximately $5 \mathrm{ng}$ genomic DNA, 1 x Dream Taq buffer (Fermentas), $1.5 \mathrm{mM} \mathrm{Mg}^{2+}, 0.1 \mathrm{mM}$ each dNTPs, $0.1 \mu \mathrm{M}$ of each primer and $0.07 \mathrm{U} / \mu \mathrm{l}$ of Dream Taq (Fermentas) for anfum6. The PCR conditions for both reactions were: $5 \mathrm{~min}$ at $94{ }^{\circ} \mathrm{C} ; 30$ cycles of $0.5 \mathrm{~min}$ at $94{ }^{\circ} \mathrm{C}, 0.5 \mathrm{~min}$ at $61{ }^{\circ} \mathrm{C}$ and, $0.5 \mathrm{~min}$ at $72{ }^{\circ} \mathrm{C}$; followed by 7 min at $72{ }^{\circ} \mathrm{C}$. A portion of the PCR products was sequenced to confirm the specificity of the reactions. The presence of anfum 8 was assessed using the primers and PCR conditions described by Susca et al. (2010) with minor modifications.

\section{Statistical analysis}

Significant differences between mean values of black aspergilli isolated per vineyards in each region and in each year were evaluated using a Kruskal-Wallis test and a Tukey-Kramer HSD test with a significance level of $\alpha=0.05$. The statistical analyses were carried out using JMP ${ }^{\circledR}$, version 8.0 (SAS Institute Inc; Cary, NC, USA) on computers running Windows 7.

\section{Results}

Meteorological data

The thermal sums and accumulated monthly rainfall amounts during the month of August for the last 32 years were calculated in the three sampled areas (Fig. 1). Most of the years, including 2008 (except in the Sarca valley) and 2010, had accumulated temperature values below $700{ }^{\circ} \mathrm{C}$ day and accumulated rainfall values greater than $50 \mathrm{~mm}$, corresponding to the first class of thermo-wetness defined by Battilani et al. (2006b). 2009 was one of the hottest years, with accumulated rainfall close to $50 \mathrm{~mm}$ and accumulated daily temperatures $>700{ }^{\circ} \mathrm{C}$ day (thermo-wetness classes 4) for the Adige valley and Rotaliana plain and an accumulated temperature value $>750{ }^{\circ} \mathrm{C}$ day (thermo-wetness class 7) for the Sarca valley.

Thermo-wetness maps of the Trentino region were constructed according to Battilani et al. (2006b) using mean daily temperatures and rainfall in August gathered during the 30 years before the sampling (Fig. 2b) and projections for the 30-year periods 2021-2050 (Fig. 2c) and 2071-2100 (Fig. 2d). Maps generated with the projections of climate conditions for the two future periods clearly show an increase of the area subject to higher thermo-wetness classes in respect to the past period. In fact, the map of Trentino region for the climatic conditions of the past 30 years is characterized by mean degree-day and rain accumulations $<700^{\circ} \mathrm{C}$ day and $>50 \mathrm{~mm}$, respectively (indicated by the green colour), in accordance with the measures obtained in the sites of sampling (Fig. 2). However, in the two predicted maps the grapevine growing area, which includes the Sarca valley, the Adige valley and the Rotaliana plain, presents a mean degree day accumulation $>750{ }^{\circ} \mathrm{C}$ day, indicated by the orange colour. Thermowetness classes with an accumulation of rainfall $<50 \mathrm{~mm}$ were never observed in the thermo-wetness maps.

Isolation of black aspergilli and species determination

During the 3 years of sampling, a total of 283 isolates belonging to the Aspergillus section Nigri were isolated from grapes grown in northern Italy by plating berries directly onto agar. Since similar results were obtained when the additional washing method was used in 2008 (data not shown), only the quicker, direct plating method for fungal isolation was used in 2009 and 2010. After 7 days of incubation each plated berry had been colonized by one or more filamentous fungus. Black aspergilli were never found to be predominant, being isolated from around $10 \%$ of the total berries, including those collected in November. Most of the rotting berries were instead colonized by Botrytis spp., Alternaria spp. and Cladosporium spp. We tested for significant differences between the mean values of black aspergilli isolated per vineyard for each sampling area in each year. A marginally significant difference $(p=0.0673)$ was observed only in vineyards in the Adige valley in 2009 (Fig. 3). This observed difference was due to the relatively large number of $A$. uvarum isolates collected in those vineyards in that year. 
Fig. 1 Summation of mean daily temperatures (a) and rain (b) in August (1-31) in the three sampling sites in the last 32 years. Black bars indicate the separation between different thermowetness classes according to Battilani et al. (2006b): $\mathrm{T}<700=$ class 1 to 3 ; $700<\mathrm{T}<750=$ class 4 to 6 ; $\mathrm{T}>750=$ class 7 to 9 .

Rain $>50=$ class $1,4,7$; $10<$ Rain $<50=$ class $2,5,8$; Rain $<10=$ class $3,6,9$ (thermal sums in ${ }^{\circ} \mathrm{C}$ day and rainfall in $\mathrm{mm}$ )
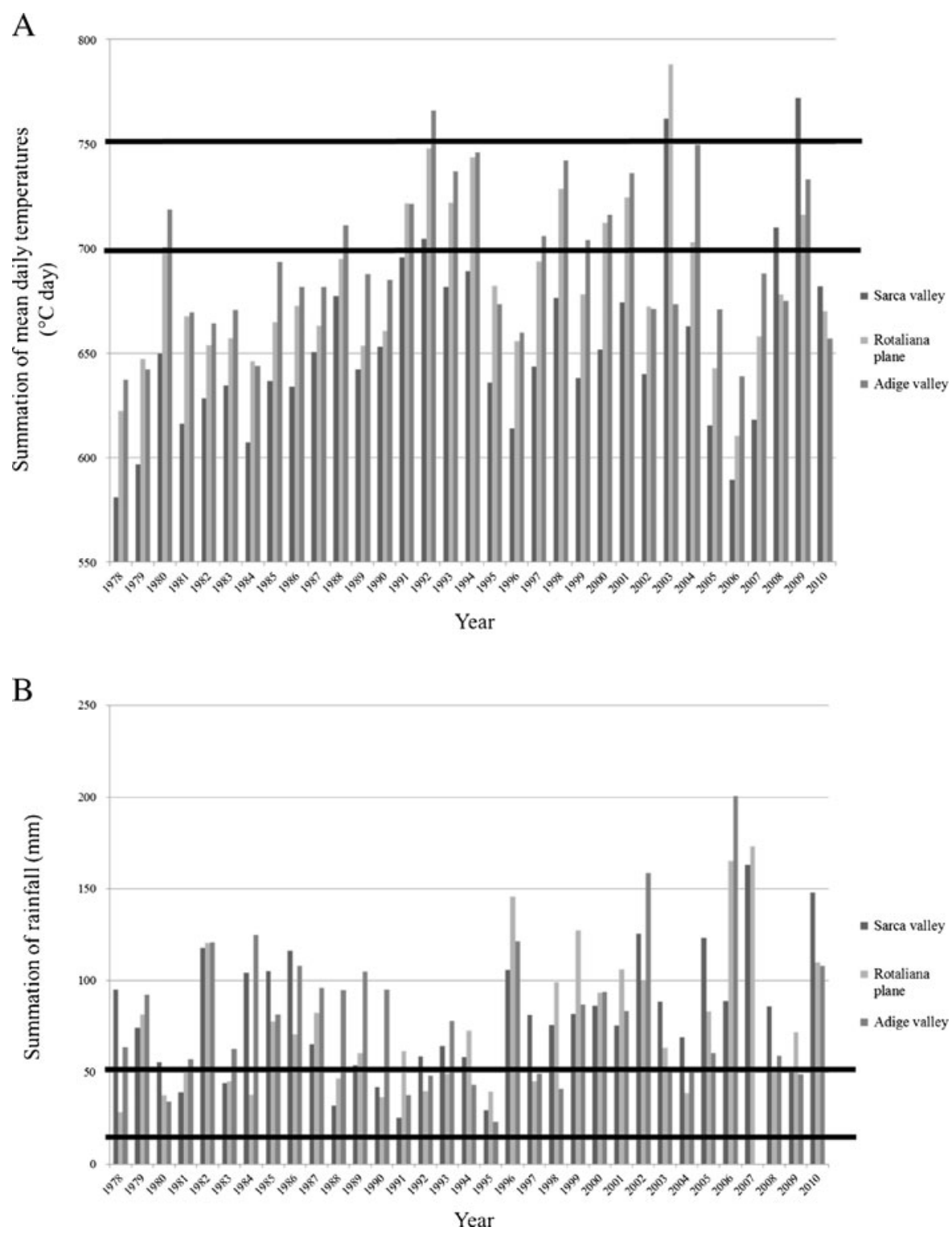

Most of the black aspergilli were classified as $A$. uvarum (183), A. niger (43) and A. tubingensis (54) based on calmodulin sequencing and the construction of phylogenetic trees. The total number of isolates of each species recovered during each year of sampling is shown in Table 2. A. uvarum isolates were more common than $A$. niger and $A$. tubingensis (A. niger aggregate) isolates in 2009 and 2010, whereas in 2008 most of the collected isolates were classified as A. niger (Fig. 4). In the 3 years of sampling, only a single $A$. carbonarius isolate was collected (September 2010).
One isolate collected in 2009 and one collected in 2010 were classified as $A$. acidus.

In vitro mycotoxin production

OTA production was detected only in the A. carbonarius isolate and in one A. niger collected in 2008 (Table 2). No A. tubingensis isolate could produce detectable amounts of OTA on either CYA or YES agars. Peaks with retention times similar to that of the OTA signal were observed 
A. Viticultural area of Trentino Region

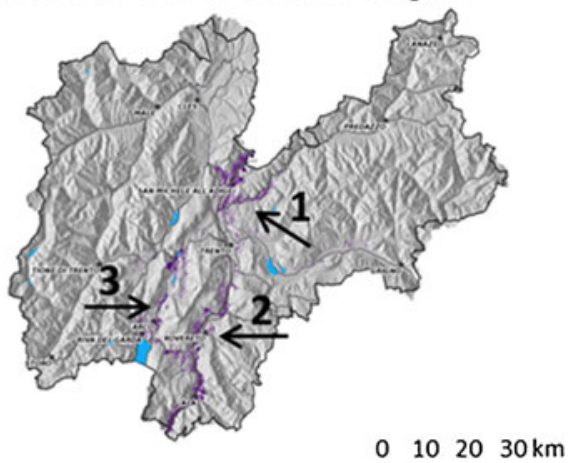

C. $2021-2050$



B. $1978-2007$

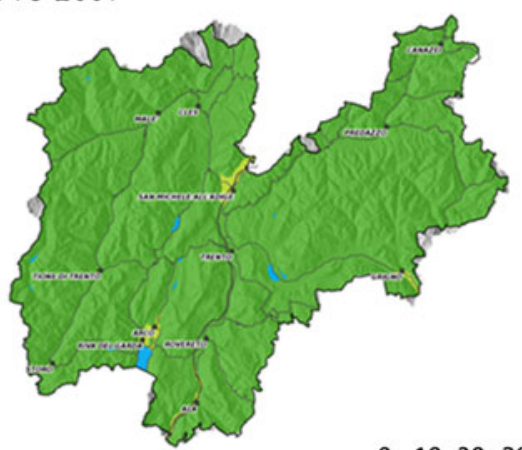

$0 \quad 102030 \mathrm{~km}$

D. $2071-2100$



$0 \quad 102030 \mathrm{~km}$
Degree day $\left({ }^{\circ} \mathrm{C}\right.$ day $)$

Rainfall (mm)

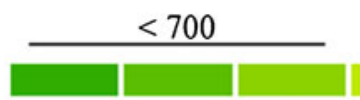

$>50 \quad 10-50<10>50$
$700-750$



$10-50<10>50$

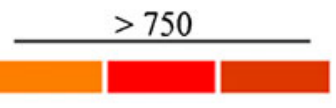

Fig. 2 Thermo-wetness maps of Trentino region generated following Battilani et al. (2006b). a Areas of sampling (1: Rotaliana plane; 2: Adige valley; 3: Sarca valley). b, c, d typical climatic conditions for the three thirty-year periods

for few extracts from both A. niger and A. tubin- run again using the second HPLC program, these gensis cultures However, when the samples were peaks were clearly separated from those of the

Fig. 3 Mean values of black aspergilli isolated per vineyard in the 3 years of sampling in three alpine valleys of Northern Italy. As indicated by the letters on the top of the columns, a marginally significant difference was observed only for vineyards of Adige valley in 2009 (Tukey-Kramer HSD test, $p=0.0673$ )




Table 2 Black aspergilli isolated from grapes of studied vineyards (Alpine valleys in Northern Italy) and their mycotoxin production ability

\begin{tabular}{|c|c|c|c|c|c|}
\hline Year & A. niger $\left(\mathrm{OTA}^{+} / \mathrm{fum}^{+}\right)$ & A. tubingensis $\left(\mathrm{OTA}^{+}\right)^{\mathrm{b}}$ & A. uvarum $^{c}$ & A. carbonarius $\left(\mathrm{OTA}^{+}\right)^{\mathrm{b}}$ & A. acidus $^{c}$ \\
\hline $2008^{\mathrm{a}}$ & $45(1 / 41)$ & $7(0)$ & 21 & $0(0)$ & 0 \\
\hline 2009 & $15(0 / 12)$ & $35(0)$ & 131 & $0(0)$ & 1 \\
\hline 2010 & $6(0 / 4)$ & $15(0)$ & 41 & $1(1)$ & 1 \\
\hline Total & $66(1 / 57)$ & $57(0)$ & 193 & $1(1)$ & 2 \\
\hline
\end{tabular}

N.B.: 2008: 12 vineyards samples; 2009 and 2010: 17 vineyards sampled

${ }^{\text {a }}$ Black aspergilli in 2008 were obtained using both plating and washing method

b Tested only for OTA production

c Not tested

OTA standards. Fumonisins production was detected in most of the A. niger isolates (91\%; Table 2). Each of the fumonisins-positive $A$. niger isolates produced $\mathrm{FB}_{2}, \mathrm{FB}_{4}$ and $\mathrm{FB}_{6}$.

Presence of mycotoxin biosynthesis genes

All $A$. niger isolates were screened for the presence of OTA and fumonisin biosynthesis genes. Amplification of an15g07920 was observed in a single ochratoxigenic A. niger isolate. Anfum1, anfum6 and anfum 8 were amplified from each fumonisins-producing $A$. niger isolate. Anfum 1 was also detected in all of the A. niger isolates, independent of their ability to produce fumonisins. Anfum6 and anfum 8 were amplified from five of the nine $A$. niger isolates that did not produce fumonisins (Table 3). Interestingly, the amplification of anfum6 and anfum 8 , when present, was observed in the same $A$. niger isolates not able to produce fumonisins (Table 3 ). The incidence of berries contaminated with fumonisins- producing $A$. niger varied from around $3 \%$ in 2008 to $1.5 \%$ in 2009 and $0.5 \%$ in 2010.

\section{Discussion}

As predicted climate change is likely to influence the distribution of pathogens, it may lead to the introduction and establishment of new pathogens in environments previously free (Magan et al. 2011). To better evaluate and prepare for the challenges that the climate change will pose to cool-climate grape-growing regions, we made a reference baseline describing the presence of black aspergilli and the species composition in vineyards in regions where the present contamination risk is low. Meteorological conditions in the alpine valleys surveyed in this study are ideal for this purpose. The analysis of meteorological measurements collected in the surveyed regions during the month of August for the last 32 years revealed only a few
Fig. 4 Black aspergilli species distribution (percentage and relative numbers of isolates) of isolates collected in the 3 years of sampling

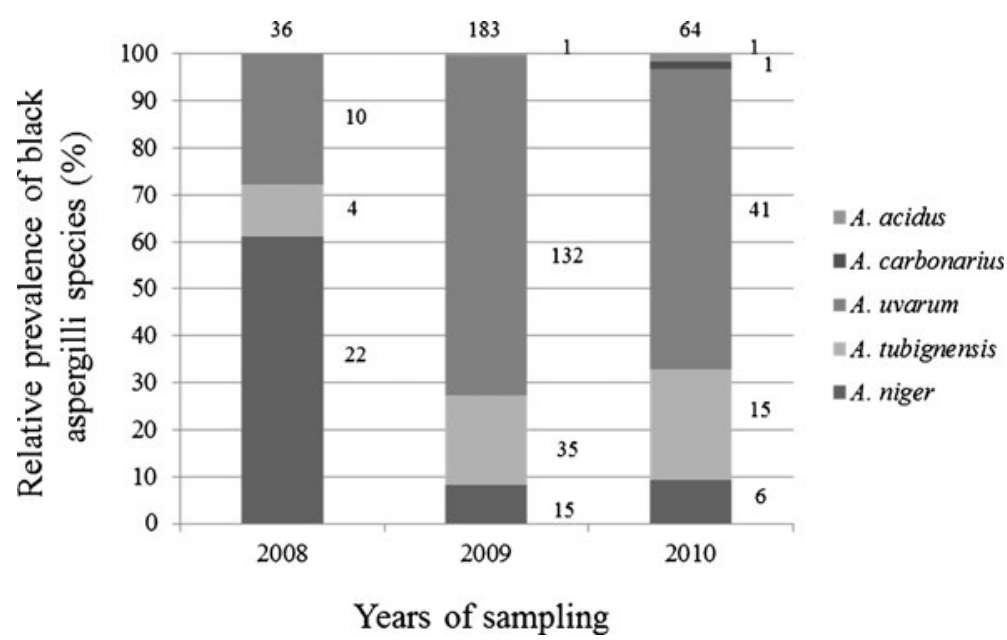


Table 3 Detection of fumonisin biosynthesis genes in Aspergillus niger strains not able to produce fumonisins. Isolates are named with the year of sampling followed by isolate number

\begin{tabular}{llll}
\hline Isolate & anfum 1 & anfum6 & anfum8 \\
\hline $08 \_11$ & + & + & + \\
$08 \_49$ & + & + & + \\
$08 \_71$ & + & - & - \\
$08 \_78$ & + & + & + \\
$09 \_23$ & + & + & + \\
$09 \_50$ & + & - & - \\
$09 \_131$ & + & - & - \\
$10 \_20$ & + & - & - \\
$10 \_21$ & + & + & + \\
\hline
\end{tabular}

cases, including 2009, of degree-day summations $>700{ }^{\circ} \mathrm{C}$ day (Fig. 1). According to Battilani et al. (2006b), the combination of a degree day summation lower than $700{ }^{\circ} \mathrm{C}$ day and accumulated rainfall higher than $50 \mathrm{~mm}$ in August, as we found in most years, is associated with a very low risk of the presence of black aspergilli on grapes. In fact, the presence of black aspergilli observed in this study (around $10 \%$ of sampled berries) was lower than those reported from vineyards in Portugal, Greece, southern Italy or Israel (20-80\% of sampled berries; Battilani et al. 2006b). The hotter summer of 2009, when conditions corresponded to the 4th thermo-wetness class for Rotaliana plain and the Adige valley and the 7th class in the Sarca valley, could be the reason for the observed increase in the incidence of black aspergilli on grapes that year (Fig. 3). However, the large number of black aspergilli isolated that year was due to the strong presence of $A$. uvarum, an atoxigenic species (Perrone et al. 2007). A. uvarum was also the most abundant species in 2010 (Fig. 4). This observation differs from the findings of other European surveys, in which the $A$. niger aggregate was the major group of aspergilli isolated from grapes (Battilani et al. 2006b; Lucchetta et al. 2010). However, A. uvarum is found more frequently on grapes from Italy than from other European countries (Battilani et al. 2006b). As expected from the literature, the incidence of A. carbonarius was extremely low. A recent study conducted in Italy also reported the absence of $A$. carbonarius from vineyards located in the Veneto region (Northern Italy; Lucchetta et al. 2010).

In vitro OTA production was detected only in the single $A$. carbonarius isolate and in one $A$. niger isolate.
This is in agreement with the reported low occurrence of ochratoxigenic strains of $A$. niger (2-20\%; Perrone et al. 2007). The ability of $A$. tubingensis species to produce OTA is still subject to debate (Nielsen et al. 2009; Storari et al. 2010). In this study no A. tubingensis isolate was found to produce detectable amounts of OTA. Some extracts of $A$. tubingensis cultures presented peaks with retention times similar to that of OTA when the first HPLC program was used (OTA peak around $6 \mathrm{~min}$ ). This observation was also reported by Nielsen et al. (2009) and represents a risk of misinterpretation of the chromatograms. Disagreement between different studies could also be due to the small quantity of toxin generally reported to be produced by A. tubingensis isolates, which is often close to the limit of detection (Perrone et al. 2006; Chiotta et al. 2011). A. uvarum isolates were not tested for OTA production, as this species is considered to be non-ochratoxigenic (Perrone et al. 2008). The production of fumonisins was detected in most of the A. niger isolates (91\%). This is in agreement with the recent literature (Nielsen et al. 2009; Noonim et al. 2009; Varga et al. 2010). In addition to $\mathrm{FB}_{2}$, we were also able to detect $\mathrm{FB}_{4}$, based on its mass, and $\mathrm{FB}_{6}$, a new positional isomer of $\mathrm{FB}_{1}$ described by Månsson et al. (2010), based on its mass and fragmentation pattern (data not shown). Although an exhaustive study would be needed to assess the occurrence of fumonisins in wines produced in the Trentino region, previous studies showed that the levels of $\mathrm{FB}_{2}$ in wines available on the European market are significantly lower than the limits posed for this mycotoxin (Logrieco et al. 2010b; Mogensen et al. 2010a). Due to the low incidence of fumonisinsproducing $A$. niger isolates ( 0.5 to $3 \%$ ) on grapes grown in Trentino region, it is expected that the levels of fumonisins in wines produced in this region will not exceed that shown in those studies.

This study confirms the low risk of contamination with OTA-producing black aspergilli for grapes grown in cool climates, as reported in the geostatistical analysis performed by Battilani et al. (2006b). However, thermo-wetness maps constructed following Battilani et al. (2006b) using climatic projections of mean daily temperatures and rainfall indicate that the climatic conditions expected for these alpine valleys are markedly different from today. The predicted increase of temperature is likely to expose vineyards to August thermal sums higher than $750{ }^{\circ} \mathrm{C}$ day (Fig. $2 \mathrm{c}$ and d). According to Battilani et al. (2006b) this is expected to cause an increase of the incidence of black aspergilli in 
general and A. carbonarius in particular. As a consequence, the risk of OTA contamination of grapes produced in these vineyards is also expected to increase, invoking the development of specific control strategies. Monitoring black aspergilli rotten berries has been suggested among the preventive measures to reduce OTA contamination in grapes (Visconti et al. 2008). In fact, vineyards "at risk" can be identified by monitoring the presence of OTA-producing black aspergilli and treated with fungicides (Hocking et al. 2007). The targeting of mycotoxin biosynthesis genes is widely used to detect and quantify mycotoxigenic pathogens in the field (Niessen 2008). Unfortunately, the OTA biosynthesis pathway of black aspergilli is not well understood (Gallo et al. 2009) and molecular methods to detect black aspergilli on grapes have been based on housekeeping genes or polyketide synthase (PKS) genes whose functions are unknown (Mulè et al. 2006; Atoui et al. 2007). These detection systems work well in the case of strong mycotoxin producers like $A$. carbonarius. However, in the case of species that are weaker OTA producers, such as $A$. niger, they may lead to false positive signals. Recently, an15g07920, a PKS annotated in the genome of $A$. niger, has been shown to be involved in OTA biosynthesis (Yamada et al. 2011). Targeting a mycotoxin biosynthesis gene can decrease the risk of false positive signals. However, the presence of biosynthesis genes without mycotoxin production is not unusual, calling for investigations on the degree of association between them (Criseo et al. 2008; Rodrigues et al. 2009). All A. niger isolates collected in the Trentino region were screened for the presence of mycotoxin biosynthesis genes. A. niger isolates collected in Trentino region in 2008 were used by Storari et al. (2010) to show that the absence of an $15 \mathrm{~g} 07920$ is related to deficient OTA production. This strong correlation was confirmed in the present study, which include A. niger isolates collected in 2009 and 2010, indicating an $15 \mathrm{~g} 07920$ as a potential good molecular target to use to detect ochratoxigenic $A$. niger in the field. However, a larger number of $A$. niger strains isolated from grapes grown in different geographical areas must be screened to confirm this correlation. The same clear relationship was not observed between the presence of the putative homologues of $F$. verticillioides fum 1, fum6 and fum 8 and the capacity for fumonisins production capacity among the A. niger isolates. Anfum1, a gene coding for a polyketide synthase, was detected in each fumonisins non-producing $A$. niger isolates. A strong presence (94\%) of anfum1 in A. niger that do not produce fumonisins was recently reported by Palumbo et al. (2011). Anfum6 and anfum8, a cytochrome P450 monooxygenase and an oxoamine synthase, respectively, were also detected in different atoxigenic strains. The presence of anfum 8 in A. niger isolated from grapes was originally examined by Susca et al. (2010). In that work, anfum 8 was absent from 37 out of 39 atoxigenic isolates. A similarly strong good correlation between gene presence and fumonisins production capacity was not observed in our study, in which anfums was amplified in five of the nine atoxigenic isolates. Although based on a reduced number of isolates, these observations suggest that the strategy of using fumonisin biosynthesis genes to detect fumonisins-producing $A$. niger strains runs a potentially high risk of yielding false positives.

In conclusion, this work presents a detailed investigation of the population of black aspergilli in vineyards located in alpine valleys in northern Italy. The occurrence of black aspergilli on grapes and the compositions of the examined Aspergillus populations are markedly different from those described in warmer regions. With only two OTA-producing strains isolated in three years of sampling, these vineyards represent an environment that currently has a very low risk of OTA contamination due to black aspergilli. The information collected here can be used as a baseline for future studies and the construction of models to predict the risk of black $A s$ pergillus infection among grapes grown in cooler regions and develop tools to monitor the entry and the establishment of populations of mycotoxin-producing black aspergilli in these areas. Since A. carbonarius is rarely found on grapes in these vineyards, both qualitative and quantitative quick molecular methods can be routinely used to detect this pathogen in these not yetcolonized environments. Moreover, an15g07920 is also a promising molecular marker for the detection of ochratoxigenic $A$. niger strains.

Acknowledgments This work was funded by the Autonomous Province of Trento, project ENVIROCHANGE, Call for Proposal Major Projects 2006. We thank Gabriela Ziltener and Renato Guidon from Plant Pathology, ETHZ, and Alberto Pellegrini, Carmela Sicher and Denise Ress from Fondazione Edmund Mach for valuable assistance in field sampling and microbiological work, Björn Studer from the Institut für Terrestrische Ökosysteme, ETHZ for valuable technical assistance with the HPLC analyses and Bernadette Vogler fo her help with the high-resolution LC-MS analyses. 


\section{References}

Atoui, A., Mathieu, F., \& Lebrihi, A. (2007). Targeting a polyketide synthase gene for Aspergillus carbonarius quantification and ochratoxin A assessment in grapes using realtime PCR. International Journal of Food Microbiology, $115,313-318$.

Battilani, P., Giorni, P., Bertuzzi, T., Formenti, S., \& Pietri, A. (2006). Black aspergilli and ochratoxin A in grapes in Italy. International Journal of Food Microbiology, 111, S53-S60.

Battilani, P., Barbano, C., Marin, S., Sanchis, V., Kozakiewicz, Z., \& Magan, N. (2006). Mapping of Aspergillus Section Nigri in Southern Europe and Israel based on geostatistical analysis. International Journal of Food Microbiology, 111, S72-S82.

Bennett, J. W., \& Klich, M. (2003). Mycotoxins. Clinical Microbiology Reviews, 16, 497-516.

Bragulat, M. R., Abarca, M. L., \& Cabañes, F. J. (2001). An easy screening method for fungi producing ochratoxin A in pure culture. International Journal of Food Microbiology, 71, 139-144.

Castellá, G., \& Cabañes, F. J. (2011). Development of a real time PCR system for detection of ochratoxin A-producing strains of the Aspergillus niger aggregate. Food Control, $22,1367-1372$.

Chiotta, M. L., Susca, A., Stea, G., Mulè, G., Perrone, G., Logrieco, A., et al. (2011). Phylogenetic characterization and ochratoxin A - fumonisin profile of black Aspergillus isolated from grapes in Argentina. International Journal of Food Microbiology, 149, 171-176.

Commission Regulation, (2005). (EC) No 123/2005 of 26 January 2005 amending Regulation (EC) No 466/2001 as regards ochratoxin A. Official Journal of the European Union L 25, 3-5. Retreived Januar 26, 2012. From http:// eurlex.europa.eu/LexUriServ/LexUriServ.do?uri=OJ: L:2005:025:0003:0005:EN:PDF.

Cordano, E., \& Eccel, E. (2011). RMAWGEN (R Multi-site Auto-regressive Weather GENerator): a package to generate daily time series from monthly mean values. $\mathrm{R}$ package version 1.2.5.1. http://CRAN.R-project.org/ package $=$ RMAWGEN.

Criseo, G., Racco, C., \& Romeo, O. (2008). High genetic variability in non-aflatoxigenic $A$. flavus strains by using Quadruplex PCR-based assay. International Journal of Food Microbiology, 125, 341-343.

Frisvad, J. C., \& Samson, R. A. (2004). Polyphasic taxonomy of Penicillium subgenus Penicillium. A guide to identification of food and air-borne terverticillate Penicillia and their mycotoxins. Studies in Mycology, 49, 1-174.

Frisvad, J. C., Smedsgaard, J., Samson, R. A., Larsen, T. O., \& Thrane, U. (2007). Fumonsin $\mathrm{B}_{2}$ production by Aspergillus niger. Journal of Agricultural and Food Chemistry, 55, 9727-9732.

Gallo, A., Perrone, G., Solfrizzo, M., Epifani, F., Abbas, A., Dobson, A. D. W., et al. (2009). Characterization of a $p k s$ gene which is expressed during ochratoxin A production by Aspergillus carbonarius. International Journal of Food Microbiology, 129, 8-15.

Gelderblom, W. C. A., Sewram, V., Shephard, G. S., Snijman, P. W., Tenza, K., van der Westhuizen, L., et al. (2007).
Structure and natural occurrence of stereoisomers of the fumonisin B series mycotoxins. Journal of Agricultural and Food Chemistry, 55, 4388-4394.

Hocking, A. D., Leong, S. L., Kazi, B. A., Emmett, R. W., \& Scott, E. S. (2007). Fungi and mycotoxins in vineyards and grape products. International Journal of Food Microbiology, $119,84-88$.

IPCC, (2007). Climate Change 2007 - Synthesis Report. Contribution of Working Groups I, II and III to the Fourth Assessment Report of the Intergovernmental Panel on Climate Change. Published by the Intergovernmental Panel on Climate Change. Retreived Januar 26, 2012. From http:// www.ipcc.ch/publications_and_data/ar4/syr/en/ contents.html.

Kållberg, P., Berrisford, P., Hoskins, B., Simmons, A., Uppala, S., Lamy-Thépaut, L., \& Hine, R. (2005). ECMWF ReAnalysis. Project Report Series 19. Era-40 Atlas. The University of Reading, UK.

Leong, S. L., Hocking, A. D., \& Scott, E. S. (2006). Effect of temperature and water activity on growth and ochratoxin A production by Australian Aspergillus carbonarius and $A$. niger isolates on a simulated grape juice medium. International Journal of Food Microbiology, 110, 209-216.

van der Linden, P., \& Mitchell, J. F. B. (2009). ENSEMBLES: climate change and its impacts: summary of research and results from the ENSEMBLES project. Exeter: Met Office Hadley Centre.

Logrieco, A. F., Ferracane, R., Cozzi, G., Haidukowsky, M., Susca, A., Mulè, G., et al. (2010). Fumonisin $\mathrm{B}_{2}$ by Aspergillus niger in the grape-wine chain: an additional potential mycotoxicological risk. Annals of Microbiology, 61, 1-3.

Logrieco, A., Ferracane, R., Visconti, A., \& Ritieni, A. (2010). Natural occurrence of fumonisin $\mathrm{B}_{2}$ in red wine from Italy. Food Additives and Contaminants, 27, 1136-1141.

Lucchetta, G., Bazzo, I., Dal Cortivo, G., Stringher, L., Bellotto, D., Borgo, M., et al. (2010). Occurrence of black aspergilli and ochratoxin A on grapes in Italy. Toxins, 2, 840-855.

Magan, N., Medina, A., \& Aldred, D. (2011). Possible climatechange effects on mycotoxin contamination of food crops pre- and postharvest. Plant Pathology, 60, 150-163.

Månsson, M., Klejnstrup, M. L., Phipps, R. K., Nielsen, K. F., Frisvad, J. C., Gotfredsen, C. H., et al. (2010). Isolation and NMR characterization of fumonisin $\mathrm{B}_{2}$ and a new fumonisin $\mathrm{B}_{6}$ from Aspergillus niger. Journal of Agricultural and Food Chemistry, 58, 949-953.

Medina, A., Mateo, R., Lopez-Ocaña, L., Valle-Algarra, F. M., \& Jiménez, M. (2005). Study of Spanish grape mycobiota and ochratoxin A production by isolates of Aspergillus tubingensis and other members of Aspergillus section Nigri. Applied and Environmental Microbiology, 71, 4696-4702.

Mogensen, J. M., Larsen, T. O., \& Nielsen, K. F. (2010). Widespread occurrence of the mycotoxin fumonisin $\mathrm{B}_{2}$ in wine. Journal of Agricultural and Food Chemistry, 58, 4853-4857.

Mogensen, J. M., Frisvad, J. C., Thrane, U., \& Nielsen, K. F. (2010). Production of fumonisin $\mathrm{B}_{2}$ and $\mathrm{B}_{4}$ by Aspergillus niger on grapes and raisins. Journal of Agricultural and Food Chemistry, 58, 954-958.

Mulè, G., Susca, A., Logrieco, A., Stea, G., \& Visconti, A. (2006). Development of a quantitative real-time PCR assay 
for the detection of Aspergillus carbonarius in grapes. International Journal of Food Microbiology, 111, 28-34.

Nielsen, K. F., Mogensen, J. M., Johansen, M., Larsen, T. O., \& Frisvad, J. C. (2009). Review of secondary metabolites and mycotoxins from the Aspergillus niger group. Analytical and Bioanalytical Chemistry, 395, 1225-1242.

Niessen, L. (2008). PCR-based diagnosis and quantification of mycotoxin-producing fungi. Advances in Food and Nutrition Research, 54, 81-138.

Noonim, P., Mahakarnchanakul, W., Nielsen, K. F., Frisvad, J. C., \& Samson, R. A. (2009). Fumonisin $\mathrm{B}_{2}$ production by Aspergillus niger in Thai coffee beans. Food Additives and Contaminants, 26, 94-100.

O’Donnell, K., Nirenberg, H. I., Aoki, T., \& Cigelnik, E. (2000). A multigene phylogeny of the Gibberella fujikuroi species complex: detection of additional phylogenetically distinct species. Mycoscience, 41, 61-78.

Otteneder, H., \& Majerus, P. (2000). Occurrence of ochratoxin A (OTA) in wines: influence of the type of wine and its geographical origin. Food Additives and Contaminants, 17, 793-798.

Palumbo, J. D., O'Keeffe, T. L., \& McGarvey, J. A. (2011). Incidence of fumonisin B2 production within Aspergillus section Nigri populations isolated from California raisins. Journal of Food Protection, 74, 672-5.

Paterson, R. R. M., \& Lima, N. (2010). How will climate change affect mycotoxins in food? Food Research International, 43, 1902-1914.

Pel, H. J., de Winde, J. H., Archer, D. B., Dyer, P. S., Hofmann, G., Schaap, P. J., et al. (2007). Genome sequencing and analysis of the versatile cell factory Aspergillus niger CBS 513.88. Nature Biotechnology, 25, 221-231.

Perrone, G., Mulè, G., Susca, A., Battilani, P., Pietri, A., \& Logrieco, A. (2006). Ochratoxin A production and amplified fragment length polymorphism analysis of Aspergillus carbonarius, Aspergillus tubingensis, and Aspergillus niger strains isolated from grapes in Italy. Applied and Environmental Microbiology, 72, 680-685.

Perrone, G., Susca, A., Cozzi, G., Ehrlich, K., Varga, J., Frisvad, J. C., et al. (2007). Biodiversity of Aspergillus species in some important agricultural products. Studies in Mycology, $59,53-66$.

Perrone, G., Varga, J., Susca, A., Frisvad, J. C., Stea, G., Kocsubé, S., et al. (2008). Aspergillus uvarum sp. nov., an uniseriate black Aspergillus species isolated from grapes in Europe. International Journal of Systematics and Evolutionary Microbiology, 58, 1032-1039.

Perrone, G., Stea, G., Epifani, F., Varga, J., Frisvad, J. C., \& Samson, R. A. (2011). Aspergillus niger contains the cryptic phylogenetic species A. awamori. Fungal Biology, 115, $1138-1150$.

Pfohl-Leszkowicz, A., \& Manderville, R. A. (2007). Ochratoxin A: an overview on toxicity and carcinogenicity in animals and humans. Molecular Nutrition \& Food Research, 51, 61-99.

Pitt, J. I., \& Hocking, A. D. (1997). Fungi and food spoilage (2nd ed.). London: Blackie Academic and Professional.

Proctor, R. H., Plattner, R. D., Desjardins, A. E., Busman, M., \& Butchko, R. A. E. (2006). Fumonisin production in the maize pathogen Fusarium verticillioides: genetic basis of naturally occurring chemical variation. Journal of Agricultural and Food Chemistry, 54, 2424-2430.
R Development Core Team. (2011). R: A language and environment for statistical computing. R Foundation for Statistical Computing, Vienna, Austria. ISBN 3-900051-07-0, http://www.R-project.org/.

Rodrigues, P., Venâncio, A., Kozakiewicz, Z., \& Lima, N. (2009). A polyphasic approach to the identification of aflatoxigenic and non-aflatoxigenic strains of Aspergillus Section Flavi isolated from Portuguese almonds. International Journal of Food Microbiology, 129, 187193.

Samson, R. A., Noonim, P., Meijer, M., Houbraken, J., Frisvad, J. C., \& Varga, J. (2007). Diagnostic tools to identify black aspergilli. Studies in Mycology, 59, 129-145.

Scott, P. M., Lawrence, G. A., \& Lau, B. P. Y. (2006). Analysis of wines, grape juices and cranberry juices for Alternaria toxins. Mycotoxin Research, 22, 142-147.

Serra, R., Abrunhosa, L., Kozakiewicz, Z., \& Venâncio, A. (2003). Black Aspergillus species as ochratoxin A producers in Portuguese wine grapes. International Journal of Food Microbiology, 88, 63-68.

Serra, R., Cabañes, F. J., Perrone, G., Castellá, G., Venâncio, A., Mulè, G., et al. (2006). Aspergillus ibericus: a new species of section Nigri isolated from grapes. Mycologia, 98, 295306.

Storari, M., Pertot, I., Gessler, C., \& Broggini, G. A. L. (2010). Amplification of polyketide synthase gene fragments in ochratoxigenic and nonochratoxigenic black aspergilli in grapevine. Phytopathologia Mediterranea, 49, 393405.

von Storch, H. (1995). Spatial patterns: EOFs and CCA. Analysis of climate variability. In: H. von Storch, \& A. Navarra (Eds.), Application of statistical techniques (pp 227-258). Springer-Verlag Berlin, Heidelberg, New York.

Susca, A., Proctor, R. H., Mulè, G., Stea, G., Ritieni, A., Logrieco, A., et al. (2010). Correlation of mycotoxin fumonisin $\mathrm{B}_{2}$ production and presence of the fumonisin biosynthetic gene fum 8 in Aspergillus niger from grape. Journal of Agricultural and Food Chemistry, 58, 92669272.

Tamura, K., Dudley, J., Nei, M., \& Kumar, S. (2007). MEGA4: molecular evolutionary genetics analysis (MEGA) software version 4.0. Molecular Biology and Evolution, 24, 1596-1599.

Tjamos, S. E., Antoniou, P. P., \& Tjamos, E. C. (2006). Aspergillus spp., distribution, population composition and ochratoxin A production in wine producing vineyards in Greece. International Journal of Food Microbiology, 111, S61S66.

Tomozeiu, R., Cacciamani, C., Pavan, V., Morgillo, A., \& Busuioc, A. (2007). Climate change scenarios for surface temperature in Emilia-Romagna (Italy) obtained using statistical downscaling models. Theoretical and Applied Climatology, 90, 25-47.

Uboldi, F., Lussana, C., \& Salvati, M. (2008). Threedimensional spatial interpolation of surface meteorological observations from high-resolution local networks. Meteorological Applications, 15, 331-345.

Valero, A., Marín, S., Ramos, A. J., \& Sanchis, V. (2005). Ochratoxin A-producing species in grapes and sun-dried grapes and their relation to ecophysiological factors. Letters in Applied Microbiology, 41, 196-201. 
Varga, J., Kocsubé, S., Suri, K., Szigeti, G., Szekeres, A., Varga, M., et al. (2010). Fumonisin contamination and fumonisin producing black Aspergilli in dried vine fruits of different origin. International Journal of Food Microbiology, 143, 143-149.

Visconti, A., Perrone, G., Cozzi, G., \& Solfrizzo, M. (2008). Managing ochratoxin A risk in the grape-wine food chain. Food Additives and Contaminants, 25, 193-202.
Yamada, O., Takara, R., Hamada, R., Hayashi, R., Tsukahara, M., \& Mikami, S. (2011). Molecular biological researches of Kuro-Koji molds, their classification and safety. Journal of Bioscience and Bioengineering, 112, 233237.

Zimmerli, B., \& Dick, R. (1996). Ochratoxin A in table wine and grape-juice: occurrence and risk assessment. Food Additives and Contaminants, 13, 655-668. 